\title{
Harmonizing the COVID-19 Pandemic Response with Economic and Social Recovery
}

\author{
Jiao Wang ${ }^{1}$; Xiaoming Shi ${ }^{1, *}$
}

\section{BACKGROUND}

In recent months, Coronavirus Disease 2019 (COVID-19) has rapidly spread to the globe, and by July 16,2020 , it has led to more than 13.4 million confirmed cases and over 0.5 million deaths (1). The pandemic has imposed enormous pressure on the healthcare system. The proportion of severe cases was estimated to be $18.5 \%$ (38.9\% for health care workers) by February 11, 2020 in China (2). Based on COVID19 severity, Zhang et al. simulated the demand for medical resources in different scenarios (3) and found that the lack of an effective pandemic response could overwhelm the healthcare system and result in deterioration in the quality of healthcare services, in overstretching frontline healthcare workers, and in a high mortality rate. Therefore, healthcare systems in countries with limited medical resources and a severe pandemic are facing greater challenges. Indeed, the lack of preparedness was observed especially in the early stage of the COVID-19 pandemic, causing a surge in the number of infected cases and highlighting the importance of the pandemic response. Furthermore, clusters of cases were reported in various places and activities when effective pandemic response measures had not been developed. For example, 7 people were infected by the same confirmed case on a 2 -hour bus ride (4) where no one wore a mask. Pung et al. investigated 3 clusters in Singapore and found that the clusters were related to either visits to shops/churches or participation in closed-door business meetings without maintaining a proper social distance (5). The cases illustrate the high risk that infections pose to economic and social activities and emphasize the importance of implementing necessary pandemic response measures during COVID-19.

An important prerequisite of reopening and recovery is adequate pandemic control capacity. Since COVID19 pandemic risk worldwide might persist in the near future, pandemic management strategies should be based on balancing economic losses due to strict restrictions and health losses due to reopening and recovery.

\section{RATIONALE AND EVIDENCE}

The COVID-19 pandemic has had far-reaching impacts on the economy and society beyond the spread of the virus. The first quarter GDP of some countries contracted by $4.8 \%-6.8 \%$ (6-7). The Asian Development Bank estimated that the collective impact of the COVID-19 crisis on the global economy will be between \$77-\$347 billion (8). The International Labour Organization (ILO) of the United Nations (UN) expected a loss of working hours equivalent to 195 million full-time workers globally in the second quarter of 2020, making many workers face a loss of income and deep poverty (9). The decrease in income will in turn harm health of the workers in the future. In addition, persistent unemployment might lead to illness, marital strife, crime, and even suicide. As of April 22, COVID-19 has caused infections in at least 48 meatpacking plants and led to the closures of at least 17 facilities and triggering concerns about national meat supply in the United States (10). Although social distancing practices could effectively interrupt the transmission of COVID-19, they also put some countries and regions in a lockdown. In Turkey, the manufacturing industry has functioned far below its capacity because of COVID-19 (11). This lockdown in many countries and regions around the globe has become the worst recession since the Great Depression and the Global Financial Crisis (12). This period, also called the Great Lockdown, gave rise to racial discrimination, theft, violence, and other negative actions that disrupt the normal order of society, and even trigger diplomatic disputes. In countries where the spread of the pandemic was basically interrupted by strict isolation strategies and non-pharmaceutical measures, huge economic losses and impacts on production and life were observed. In the least developed countries, the socioeconomic 
impacts further deteriorated poor health care infrastructure and drained limited resources to fight the crisis. Unfortunately, continued or intermittent social distancing may be extended to 2022 without other interventions (13). Therefore, there is an urgent need for reopening the economy under appropriate protective measures.

Lifting COVID-19 restrictions inappropriately may expose the public to a high risk of infection. Even though Repubic of Korea gradually lifted restrictions following weeks of social distancing measures and careful surveillance, new clusters of 119 total cases were linked to nightclubs in Seoul in May 2020 (14). Due to the differences in the time of onset of COVID-19, pandemic responses, socioeconomic development levels, population density, public awareness, and environmental conditions, different countries and regions might be at different stages of the pandemic. A uniform approach could hardly meet the need for the recovery under the diverse conditions and pandemic stages, and may further hinder the economic and social recovery. Therefore, a region-specific, multilevel targeted risk management approach is proposed here to harmonize pandemic response with economic and social recovery amid the COVID-19 pandemic.

\section{RISK-BASED PANDEMIC MANAGEMENT STRATEGIES FOR ECONOMIC AND SOCIAL RECOVERY}

In order to prepare for economic and social reopening and recovery, a pandemic management strategy based on risk levels of individual regions or counties is proposed in Table 1 . The local classification of risk levels should be based on a comprehensive consideration of confirmed cases, deaths, population density, climate conditions, and other factors that would provide rationality for risk-level classification. The risk-based pandemic management strategy recommended in this study was based on the risk adjusted pandemic response established by the
National Health Commission of China because the curve of cumulative cases has been flattened since March in China without any sign of rebound, which implies that this strategy is effective in controlling the COVID-19 pandemic. However, it should be pointed out that it is difficult to apply one strategy to all countries and regions because of the significant differences in politics, economy, culture, health, and social management among countries. Therefore, reopening plans and pandemic response in other countries such as the United States, Republic of Korea, Singapore, etc. were also referred to improve the applicability of the management strategy. This study emphasized that the risk level plays an important role when countries formulate local strategies in order to harmonize the COVID-19 pandemic response with economic and social recovery. Under this principle, the specific situation of different countries and regions must be considered to explore differentiated strategies.

\section{REOPENING THE ECONOMY GRADUALLY AND ORDERLY}

Reopening the economy strategically amid the pandemic is to mitigate the economic crisis caused by COVID-19. Priority should be given to essential industries such as medical supplies, energy, food, and emergency responses. The resumption of lower priority work could be appropriately delayed, particularly in high-risk regions. In most countries, tourist-dependent industries and retailers have been hit particularly hard by COVID-19. However, the pandemic is also an opportunity for emerging industries, such as telehealth and telemedicine, big data analytics, and mobile robotics, all of which have been showing strong growth potential.

Fiscal, monetary, and financial policies should be updated. They are supposed to support demand, incentivize firm hiring, and improve balance sheets to aid the recovery. Coordinated fiscal stimuli across countries with fiscal space would magnify the benefits.

TABLE 1. Region-specific risk levels and management strategies during COVID-19 pandemic.

\begin{tabular}{lll}
\hline Risk Level & Required Conditions for Each Risk Level & Risk Management Strategies \\
\hline \multirow{2}{*}{ Low } & $\begin{array}{l}\text { COVID-19 cases continuously decreasing for 14 } \\
\text { consecutive days. Adequate hospital capacity and } \\
\text { medical resource supply. }\end{array}$ & $\begin{array}{l}\text { Prevent the spread of COVID-19 from external sources and } \\
\text { resume work and normal life as soon as possible. }\end{array}$ \\
Medium & $\begin{array}{l}\text { Growth of the number of new cases slows without } \\
\text { evidence of a rebound. }\end{array}$ & $\begin{array}{l}\text { Prevent the spread of COVID-19 from both external and } \\
\text { internal sources with precautions. Orderly and conditionally } \\
\text { resume work and normal life. }\end{array}$ \\
High & $\begin{array}{l}\text { No downward trajectory of COVID-19 cases reported } \\
\text { within 14 days or rebound reported. }\end{array}$ & \begin{tabular}{l} 
Resumption is not recommended. \\
\hline
\end{tabular}
\end{tabular}


Moratoria on debt repayments and debt restructuring may need to continue during the recovery phase. In areas with a high poverty level, the coordination of national tax policies should be improved and economic growth should be boosted to strengthen national health systems. Budget-constrained countries and regions could seek help from international financing facilities. Existing monetary arrangements and financial-sector regulations that hamper external competitiveness should be reformed to enable exchange-rate flexibility. Comprehensive new debt-relief schemes could be considered with good governance.

It is necessary to implement the employment priority policy and adjust the policy intensity according to employment situations. Employees in low-risk areas should be encouraged to return to work. Accordingly, employers should be encouraged to consider point-topoint transit services to reduce the infection risk in the public transportation systems. It should be pointed out that flexible employment through multiple channels favors the economy reopening. For unemployed people, online registration of unemployment and application for unemployment insurance are recommended to meet a basic living standard.

\section{LIFTING COVID-19 RESTRICTIONS CONDITIONALLY}

To coordinate with the conditional reopening of the economy, relevant COVID-19 restrictions should be lifted gradually. According to evolving risk levels, differentiated precautions should be taken based on local conditions. Some necessary living services and outdoor public places should remain operating or open during the pandemic in order to satisfy basic living requirements. In low-risk areas, these places could gradually resume normal operations, though it should not be allowed in medium-risk areas until effective measures have been carried out to clean and disinfect the environment, monitor population health, limit population density, and reduce gatherings. Loosening restrictions will accelerate the flow of people. It is recommended to ensure a seamless and hermetic process for managing the quarantine and monitoring travelers particularly from high-risk areas in addition to strict management and supervision measures in public transportation stations and vehicles. Meanwhile, governments should protect agricultural production regardless of risk level. Since farmlands basically belong to open areas with ideal ventilation, inapplicable restrictions could be eliminated to ensure agricultural production and adequate food supply.

\section{DEVELOPING COMPREHENSIVE RECOVERY STRATEGIES}

In order to provide support for lifting restrictions and reopening the economy, it is critical to develop comprehensive recovery strategies for the mitigation, containment, and control of COVID-19. Different strategies have already been adopted by different countries and regions, such as testing, tracing, and supported isolation (TTSI) adopted by the US, adaptive triggering strategy used by the UK, and the risk-adjusted strategy adopted by the WHO Western Pacific Region. Early detection, early reporting, early isolation, and early treatment are recommended to control infection sources and interrupt the transmission route. In low-risk areas, normal health care services, such as outpatient care, emergency clinic, hospitalization, and surgery, should be fully resumed. In medium-risk areas, they should be resumed in an orderly manner while taking necessary precaution measures. In high-risk areas, hospital capacity should be surged and health institutions should also focus on research and development of effective drug and vaccines. Compliance with strict preventive measures should be improved especially for vulnerable groups. Psychological services should also be provided for patients, family members of patients or deceased patients, and frontline health care workers to protect mental health and further promote social harmony and stability.

The COVID-19 pandemic may go far beyond an economic and social crisis and may become a health equity crisis. The failures in health equity may lead to long term existence of COVID-19 in communities. Thus, priority should be given to marginalized and vulnerable groups including children, older adults, refugees and migrants, poorer people, people with disabilities, people in detention, minorities, and lesbian, gay, bisexual, transgender, and intersex (LGBTI) people. These groups are more likely to be exposed to risks, more vulnerable to COVID-19 infection, and less likely to have the access to health care services and protective equipment. To cope with health inequity issues, inter-/intra-cooperation is encouraged to balance health resources in different countries and regions. In addition, the lack of community capacity and mobilization in the deprived 
regions may be another key bottleneck to provide timely assistance to patients and their families (15).

\section{DISCUSSION}

Whether COVID-19 can be controlled or not is determined by the weakest health system and the most vulnerable groups in this interconnected world. In addition, different countries and regions are at various stages of the pandemic. Thus, a region-specific and multi-level targeted risk management approach should be emphasized while inter-/intra-national cooperation should be encouraged to formulate pandemic responses and accelerate the development of drugs and vaccines. With the occurrence of emerging infectious diseases, health concerns have become strategic issues related to national security. As the authorities dealing with health issues, health departments are suggested to provide technical support in coordinating with other relevant departments such as the market supervising departments, civil affairs departments, and agriculture departments. The implementation of a national strategy must be adjusted to satisfy local needs while local governments are recommended to develop flexible strategies harmonizing pandemic responses with social and economic recovery. Last but not least, although mortality rate of the youth is relatively low and the proportion of the asymptomatic cases is relatively high, infectious cases will indirectly increase the health risks to older adults. Therefore, compliance improvements across society is necessary to ensure the implementation of personal precautions during the pandemic.

Acknowledgments: The authors would like to acknowledge Prof. Zhiqiang Deng for insightful advices and help in improving the writing.

Conflict of interests: We declare no coonflict of interests.

doi: $10.46234 / \mathrm{ccdcw} 2020.171$

\# Corresponding author: Xiaoming Shi, shixm@chinacdc.cn.

\footnotetext{
${ }^{1}$ China CDC Key Laboratory of Environment and Population Health, National Institute of Environmental Health, Chinese Center for Disease Control and Prevention, Beijing, China.
}

Submitted: July 08, 2020; Accepted: July 17, 2020

\section{REFERENCES}

1. World Health Organization. Coronavirus disease 2019 (COVID-19) situation report-153. 2020. https://www.who.int/emergencies/diseases/ novel-coronavirus-2019/situation-reports.[2020-06-21].

2. Epidemiology Working Group for NCIP Epidemic Response, Chinese Center for Disease Control and Prevention. The epidemiological characteristics of an outbreak of 2019 novel coronavirus diseases (COVID-19) in China. Chin J Epidemiol 2020;41(2): 145-51. http:// dx.doi.org/10.3760/cma.j.issn.0254-6450.2020.02.003. (In Chinese).

3. Zhang T, Wu H, Wang L, Yang W. Scenario-based study of medical resource requirement rapid assessment under the COVID-19 pandemic. Chin J Epidemiol 2020;41. http://dx.doi.org/10.3760/cma.j.cn11233820200401-00488. (In Chinese).

4. Luo KW, Hai Z, Xiao SL, Yang H, Jing XP, Wang H, et al. An epidemiological investigation of 2019 novel coronavirus disease through aerosol-borne transmission by public transport. Pract Prev Med 2020;27. https://kns.cnki.net/KCMS/detail/43.1223.r.20200304.1634. 008.html. (In Chinese).

5. Pung R, Chiew CJ, Young BE, Chin S, Chen MIC, Clapham HE, et al. Investigation of three clusters of COVID-19 in Singapore: implications for surveillance and response measures. Lancet 2020;395(10229): 1039 - 46. http://dx.doi.org/10.1016/S0140-6736(20)30528-6.

6. U.S. Bureau of Economic Analysis. Gross domestic product, Fourth quarter and Year 2019 (Third Estimate); corporate profits, Fourth Quarter and Year 2019. 2020. https://www.bea.gov/news/2020/grossdomestic-product-fourth-quarter-and-year-2019-third-estimatecorporate-profits.[2020-03-26].

7. Li X, Zhou LX. Economy rebounding after drop. China Daily; 2020. http://www.chinadaily.com.cn/a/202004/17/WS5e990d9da3105d50a3 d16e20.html.[2020-04-29].

8. The Borgen Project. How the COVID-19 crisis is impacting global poverty. 2020. https://borgenproject.org/covid-19-crisis/.[2020-05-18].

9. International Labour Organization. ILO monitor: COVID-19 and the worldofwork.2ndedition.2020.https://www.ilo.org/global/topics/corona virus/impacts-and-responses/WCMS_740877/lang--en/index.htm. [2020-05-18].

10. Bagenstose K. Coronavirus at meatpacking plants worse than first thought, USA Today investigation finds. 2020. https://www.usatoday. com/in-depth/news/investigations/2020/04/22/meat-packing-plantscovid-may-force-choice-worker-health-food/2995232001/.[2020-0424].

11. Xinhua. Spotlight: Turkey's manufacturing industry functions far below capacity amid COVID-19 outbreak. 2020. http://www.xinhuanet. com/english/2020-04/27/c_139012713.htm.[2020-04-29].

12. Gopinath G. The Great Lockdown: worst economic downturn since the Great Depression. Internatioanl Monetary Fund; 2020. https://blogs. imf.org/2020/04/14/the-great-lockdown-worst-economic-downturnsince-the-great-depression/.[2020-04-17].

13. Kissler SM, Tedijanto C, Goldstein E, Grad YH, Lipsitch M. Projecting the transmission dynamics of SARS-CoV-2 through the postpandemic period. Science 2020;368(6493):860 - 8. http://dx.doi.org/10.1126/ science.abb5793.

14. Yonhap News Agency. (2nd LD) Infections linked to Itaewon clubs soar to 119 , stoke fears on additional transmission. 2020. https://en. yna.co.kr/view/AEN20200513004752315. [2020-05-13].

15. Wang ZC, Tang K. Combating COVID-19: health equity matters. Nat Med 2020;26(4):458. http://dx.doi.org/10.1038/s41591-020-0823-6. 